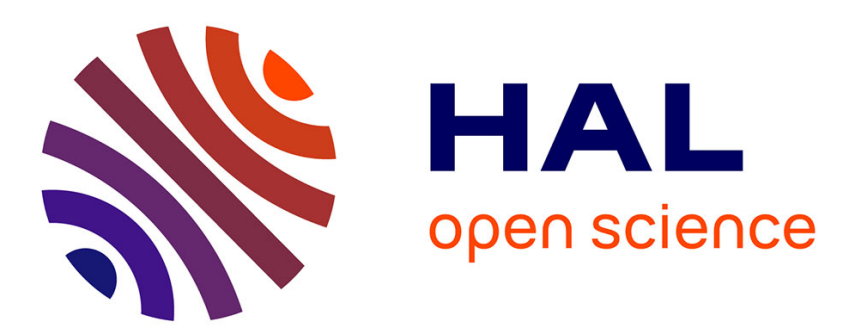

\title{
Laser induced chemical vapour deposition of TiN coatings at atmospheric pressure
}

\author{
Y. Croonen, G. Verspui
}

\section{To cite this version:}

Y. Croonen, G. Verspui. Laser induced chemical vapour deposition of TiN coatings at atmospheric pressure. Journal de Physique IV Proceedings, 1993, 03 (C3), pp.C3-209-C3-215. 10.1051/jp4:1993328 . jpa-00251385

\section{HAL Id: jpa-00251385 https://hal.science/jpa-00251385}

Submitted on 1 Jan 1993

HAL is a multi-disciplinary open access archive for the deposit and dissemination of scientific research documents, whether they are published or not. The documents may come from teaching and research institutions in France or abroad, or from public or private research centers.
L'archive ouverte pluridisciplinaire HAL, est destinée au dépôt et à la diffusion de documents scientifiques de niveau recherche, publiés ou non, émanant des établissements d'enseignement et de recherche français ou étrangers, des laboratoires publics ou privés. 


\title{
Laser induced chemical vapour deposition of TiN coatings at atmospheric pressure
}

\author{
Y.H. CROONEN and G. VERSPUI
}

Nederlandse Philips Bedrijven B.V., CFT Techinology, Building SAQ 1708, 5600 MD Eindhoven, The Netherlands

\begin{abstract}
.
Laser induced Chemical Vapour Deposition of a wide variety of materials has been studied extensively at reduced pressures. However, for this technique to be economically and industrially applicable, processes at atmospheric pressure are preferred. A model study was made on the substrate-coating system molybdenum-titaniumnitride focussing on the feasibility to deposit TiN films locally at atmospheric pressure. The results of this study turned out to be very promising.

A Nd-YAG laser beam $(\lambda=1064 \mathrm{~nm})$, directed perpendicular to the substrate, is used to locally heat the substrate (pyrolytic atmospheric pressure Laser induced Chemical Vapour Deposition). The reactive atmosphere consists of TiCl, $\mathrm{N}_{2}$ and $\mathrm{H}_{2}$. The Laser Chemical Vapour Deposited nitride coating is characterized by SEM, EDAX, XRD, XPS, SAM and microhardness tests. The results show that the coatings are pure, polycrystalline, stoichiometric TiN with a hardness in the range 1900 to 2300 HV. The influence of laser irradiation parameters on the temperature distribution induced in molybdenum and on the deposit shape, spatial distribution and microstructure of TiN films has been studied. A fast laser spot pyrometer was built for the in-situ temperature measurements. Depending on the deposition conditions, different types of profiles, microstructures and distribution widths are observed. Two examples of atmospheric pressure Laser CVD deposited TiN films on 3D-objects are given.
\end{abstract}

\section{INTRODUCTION.}

The term Laser induced Chemical Vapour Deposition (LCVD) refers to a wide variety of processes in which material is deposited from the gas phase under the influence of laser irradiation. Deposition of several metals (1-13) as well as metaloxides, -nitrides, -carbides and -borides (14-23) has already been accomplished by LCVD. The capability of LCVD to deposit coatings very locally and to combine the advantages of high temperature deposition (high effective growth rates, good adhesion, little contamination of the film) with the strongly localized heat and chemical treatments is particular convenient for applications in the micromechanics and microelectronics field.

The LCVD processes are based on the activation (either pyrolytic or photolytic) of chemical reactions by a laser beam. In pyrolytic LCVD, the laser serves as a heat source to locally heat the substrate in order to thermally drive the reaction. Photolytic LCVD on the other hand involves the resonant absorption of the laser radiation by the precursor molecules. As in the more conventional methods for making thin films, vacuum LCVD processes are the most widely known and well respected. However, the demand for more production oriented and cost effective thin film processes has increased the interest in atmospheric LCVD processes. In this study, we will report on the characterization of TiN coatings deposited locally on molybdenum using pyrolytic LCVD at atmospheric pressure. Deposition of TiN on various 3D-formed tool steels has also been investigated. Films of TiN are extensively used in many applications not only because of their wear resistance properties but also because of their optical and diffusion barrier properties.

Contrary to conventional CVD processes where the whole substrate material is uniformly heated to a high temperature in the environment of reactant molecules, only a small area of the substrate is heated during pyrolytic LCVD processes and a temperature distribution is induced in the substrate. Favourable consequences are the observed spatial control of deposited films and the reduced thermal load of the substrate materials.

However, the profiles and microstructures of the deposits were found to depend strongly on the surface temperature induced by the laser beam. In this paper we will correlate the microstructure, deposit shape and spatial distribution of the TiN films with the laser irradiation parameters. 
Pyrolytic LCVD of TiN films at atmospheric pressure was carried out in a small stainless steel reactor consisting of a gas feedthrough, a laser entry window, a pressure meter connection, an outlet to a 1 tary pump and an exhaust line connected to a $\mathrm{NaOH}$ scrubber (fig.1). A $250 \mathrm{~W}$ Lumonics JK $702 \mathrm{Nd}$-Y AG laser beam was irradiated on the substrates at perpendicular incidence. The laser operates at $1064 \mathrm{~nm}$, has variable pulse lengths of $0.5-20 \mathrm{~ms} .$, pulse energies up to $40 \mathrm{~J}$ and pulse shaping possibilities. The laser beam is transported via a glass fibre $(600$ $\mu m$ diameter) to a focussing head. This head in turn is fixed to an $\mathrm{XYZ}$ microbank. A viewing system consisting of a CCD camera and a monitor makes it possible to look at the laser spot on the substrate surface during deposition.

A self-made laser spot pyrometer (uncompensated for emissivity changes) capable of fast (10 msec. time constant) in-situ temperature measurements was build as an extension to the standard laser head. The system has two optical branches: one for the laser beam handling and one for the handling of the thermal radiation. The branches converge into an integrated laser head which delivers the laser energy to the workpiece and also catches visible and near infra-red (NIR) radiation coming from the heated surface (24). The NIR part of the light is focused on an optical fibre. The construction is such that the fibre end is situated in an image field conjugated to the substrate. It can be moved $5 \times 5 \mathrm{~mm}$. by micrometer screws, so that the NIR radiation can be taken from

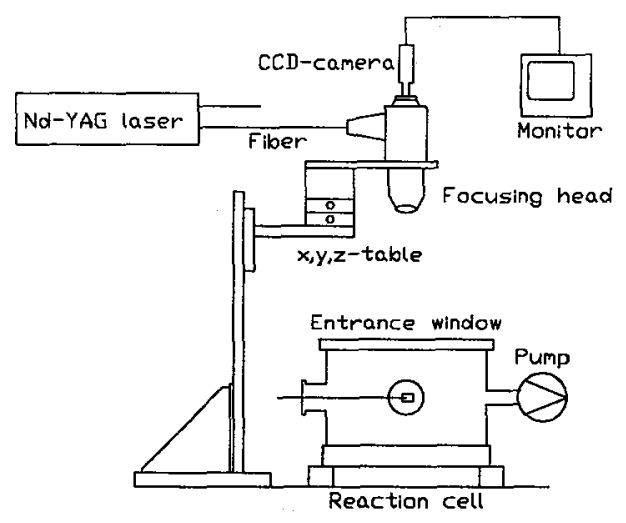

Figure 1: Experimental LCVD deposition cell a reproducible location of the sample. In most cases this location is taken aligned with the laser spot, so that the highest temperature region is monitored. It is however posssible to study the temperature distribution profile in the vicinity of the laser spot by shifting the fibre position and taking the micrometer readings. It can be anticipated that growing a TiN film on a substrate or even simply heating such a substrate brings about a change in emissivity. Because the pyrometer set-up used in this work is not corrected for such emissivity changes, temperature values are only measured prior to any deposition and trends rather than absolute values are used in discussing the results.

Deposition experiments were carried out on $10 \mathrm{~mm} \times 5 \mathrm{~mm} \times 39 \mu \mathrm{m}(\mathrm{L} \times \mathrm{W} \times \mathrm{H})$ molybdenum strips and various tool steels. Pretreatment of the molybdenum strips included:

- reduction in a $\mathrm{N}_{2} / \mathrm{H}_{2}(7 \%)$ atmosphere at $1050^{\circ} \mathrm{C}$ during $20 \mathrm{~min}$.

- cooling down of the strips in a $\mathrm{N}_{2} / \mathrm{H}_{2}(7 \%)$ atmosphere during $20 \mathrm{~min}$.

All strips were used without additional cleaning. The tool steels were ultrasonically degreased in a Nebol solution.

TiN films were deposited in a reactive atmosphere of $\mathrm{TiCl}_{4}, \mathrm{~N}_{2}$ and $\mathrm{H}_{2}$ according to the overall chemical reaction: $\mathrm{TiCl}_{4}+1 / 2 \mathrm{~N}_{2}+2 \mathrm{H}_{2} \rightarrow \mathrm{TiN}+4 \mathrm{HCl}$

Prior to any deposition experiment, the deposition cell is evacuated to a pressure of 0.004 mbar by the rotary pump. Next the pump is disconnected from the deposition cell by means of a manual operated valve.

The cell is then refilled with $\mathrm{N}_{2}$ till atmospheric pressure and the bypass to the $\mathrm{NaOH}$ scrubber is opened.

The respective gases $\mathrm{N}_{2}$ and $\mathrm{H}_{2}$ are monitored and controlled by means of electronic mass flow controllers and pneumatic solenoid valves. The $\mathrm{TiCl}_{4}$ dosing equipment consists of a gas bubbler and recondensation jacket with temperature control. The $\mathrm{TiCl}_{4}$ flow is controlled by the temperature of the $\mathrm{TiCl}_{4}$ bubbler $\left(40^{\circ} \mathrm{C}\right)$ and the amount of $\mathrm{H}_{2}$ carrier gas passing through this bubbler. The degree of saturation of the $\mathrm{H}_{2}$ carrier gas with the $\mathrm{TiCl}_{4}$ vapour is assumed to be constant. The gas stream saturated with $\mathrm{TiCl}_{4}$ is fed to the reactor through heated $\left(70^{\circ} \mathrm{C}\right)$ gas lines to prevent premature condensation of the $\mathrm{TiCl}_{4}$. The experimental gas flows used are: $\mathrm{N}_{2}: 112.5 \mathrm{sccm}, \mathrm{H}_{2 \text { carr: }}: 40.0 \mathrm{sccm}, \mathrm{N}_{2} / \mathrm{H}_{2}: 1.5$. The deposition experiments are then started with selected laser irradiation parameters.

The microstructure of the TiN films has been observed by SEM. Using X-ray Diffraction (XRD), X-ray Photo electron Spectroscopy (XPS), Scanning Auger Microprobe (SAM) and EDAX analysis the chemical composition and stoichiometry of the TiN films were determined. SEM cross-sectional analyses were used to assess layer thickness and layer thickness distribution. 


\subsection{Deposition of TiN on molybdenum.}

Characteristic gold coloured coatings were produced and analyzed by EDAX mainly to ensure that no significant amounts of impurities were present in the coatings. This was confirmed by the EDAX spectra. The intensities and the appearances of the peaks in the XRD pattern of the deposited films were consistent with polycrystalline stoichiometric TiN (osbornite).

With XPS and SAM the chemical composition and the light-element chemical bonding of the TiN films were investigated before as well as after sputtering.

Chemical compositions as calculated from the XPS spectra are given for two representative films in Table I.

Table I: $\quad$ XPS analysis data of TiN films deposited at $300 \mathrm{~Hz}, 0.5 \mathrm{~ms}$. (laser power $=42 \mathrm{~W}$ )

Deposition time: $60 \mathrm{sec}$.

a) no pretreatment of the coating surface.

b) coating surface pre-sputtered $(10-14 \mathrm{~nm}$ removed).

\begin{tabular}{|c|c|c|c|c|c||}
\hline Substrate & Ti at\% & N at\% & C at\% & O at\% & Cl at\% \\
\hline 1a & 25.57 & 23.11 & 20.15 & 29.73 & 1.33 \\
\hline $2 \mathrm{a}$ & 21.79 & 17.70 & 28.52 & 30.39 & 1.24 \\
\hline 1b & 44.56 & 39.73 & 3.08 & 12.05 & 0.33 \\
\hline 2b & 46.44 & 41.46 & 3.59 & 8.07 & 0.14 \\
\hline
\end{tabular}

At the surface of the films the elements $\mathrm{Ti}, \mathrm{N}, \mathrm{C}, \mathrm{O}$ and $\mathrm{Cl}$ are detected. After removing the uppermost 10-14 $\mathrm{nm}$ of the layer by sputtering Ti, N, $\mathrm{O}$ and a few at\% $\mathrm{C}$ are detected. With regard to the light-element chemical bonding, the XPS nitrogen 1 s peak was found at a binding energy consistent with titanium- bound nitrogen $(397.7 \mathrm{eV})$. The Ti $2 \mathrm{p}$ spectrum has a typical satellite structure with Ti 2 p $1 / 2$ and Ti 2 p $3 / 2$ peaks at binding energies of about $461 \mathrm{eV}$ and $455.4 \mathrm{eV}$ respectively. Both values agree with reported chemical shifts from Ti-metal peaks bound to $N$.

The XPS oxygen peak found at $531 \mathrm{eV}$ after sputtering has probably to be assigned to $\mathrm{TiO}_{2}$ as corraborated by the peak at $463.5 \mathrm{eV}$ in the Ti $2 \mathrm{p}$ spectrum. Carbon at the surface before sputtering exists as $\mathrm{C}-\mathrm{H}(80 \%)$ and $\mathrm{C}-\mathrm{O}(20 \%)$ bonds and is attributed to contamination by the XPS loadlock system. After sputtering part of the C-H and C-O remains. Shading effects caused by the rough molybdenum surface were thought to be responsible for the occurence of the carbon and oxygen after sputtering. To exclude shading effects by the surface SAM analysis was performed. At the surface the elements Ti, $N, C, O$ and $\mathrm{Cl}$ were found; at a depth of $150-200 \mathrm{~nm}$ only $\mathrm{Ti}$ and $\mathrm{N}$ could be detected.

The micro-hardness of the TiN coatings was measured with a Vickers microhardness indenter. Seven indentions with $2 \mathrm{~g}$ load were made on cross-sectioned layers. The resulting indention diagonals $\mathrm{D}$ were then measured using brightfield, dark-field and scanning electron microscopy. A hardness in the range $1900-2300 \mathrm{HV}$ was found.

The surface-profiles, morphologies and spatial distribution of the laser-deposited TiN films were strongly influenced by the laser output power density i.e. the temperature. For the depositions on molybdenum the laser power densities were varied between $5 \times 10^{3} \mathrm{~W} / \mathrm{cm}^{2}$ and $25 \times 10^{3} \mathrm{~W} / \mathrm{cm}^{2}$. Two different types of profiles were observed depending on the laser pulse output power. At low laser powers ( $\leq 35 \mathrm{~W}$ ) small Gaussian-type deposits of TiN were observed. The layer thickness of these deposits gradually decreased from the centre towards the edges. At high laser powers ( $\geq 35 \mathrm{~W}$ ) volcano-like deposits were obtained. The cross-sectional profiles in these cases showed an inhomogeneous layer thickness distribution with thickness increasing from the centre towards the edges. The film thickness ratio $D_{d} / D_{e}$ (where $D_{c}$ represents the thickness at the centre and $D_{e}$ the thickness at the edge of the deposit) as a function of laser output power is shown in figure 2. A transition from Gaussian-type to

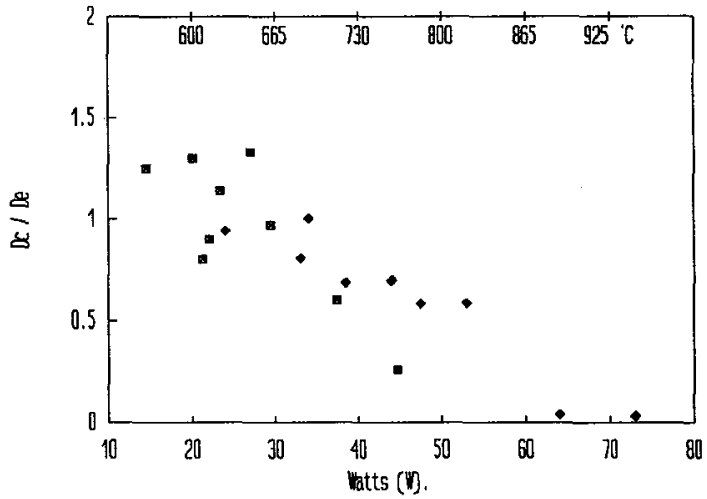

Figure 2: $\mathrm{D}_{\mathrm{c}} / \mathrm{D}_{\mathrm{e}}$ ratio of $\mathrm{TiN}$ deposits on molybdenum as a function of laser mean output power. 
volcano-like deposits is observed with increasing laser mean output power i.e. increasing temperature.

The spatial distribution width of all the deposits increased with increasing laser mean output power (fig.3). Moreover, TiN films deposited at high laser powers consisted of several asymmetric regions visual with the naked eye where different

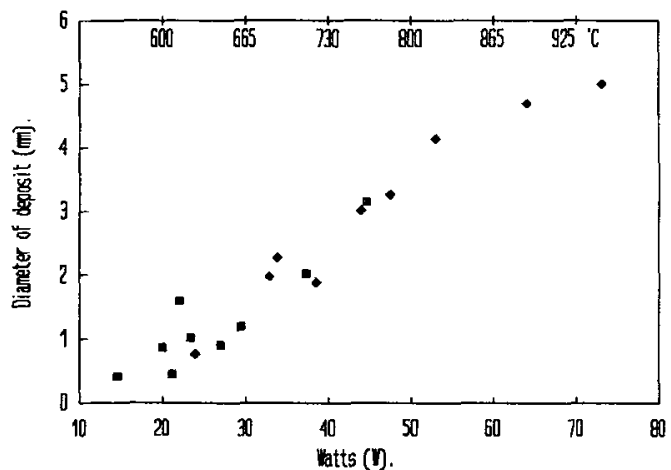

Figure 3 : Diameter of TiN deposits on molybdenum as a function of laser mean output power.

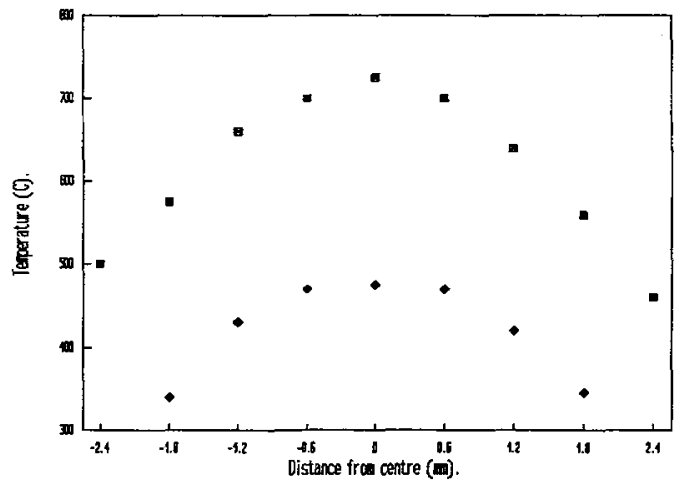

Figure 4 :Temperature profile induced in molybdenum at $17.6 \times 10^{3} \mathrm{~W} / \mathrm{cm}^{2}$ (upper curve )and $9 \times 10^{3} \mathrm{~W} / \mathrm{cm}^{2}$ (lower curve). Displacement of IR-fibre over the lenght.

microstructures have grown. In the peripheral zone a granular morphology is seen, changing to a nodular-like morphology in the middle of the deposit. In the centre of the spots a plateletlike morphology is observed.

Temperature measurements on bare molybdenum in the absence of $\mathrm{TiCl}_{4}$ performed using the self-built pyrometer showed that the Nd-YAG laserbeam induced a Gaussian-like temperature profile in the substrates under all irradiation conditions studied. Figures 4 and 5 give representative examples of measured surface temperature profiles at laser power densities of $9 \times 10^{3}$ $\mathrm{W} / \mathrm{cm}^{2}$ and $17.6 \times 10^{3} \mathrm{~W} / \mathrm{cm}^{2}$ respectively. With an increase in laser output power the substrate temperature is seen to increase such that the temperature was a maximum at the centre of the beam. In addition to the laser mean power the measured temperatures in the centre of the laser spot are indicated in figures 2 and 3 . Deposition is only possible in those regions of the substrate where the temperature corresponds to the threshold temperature for decomposition of the precursor. The increase in distribution width with laser output power is attributed to the

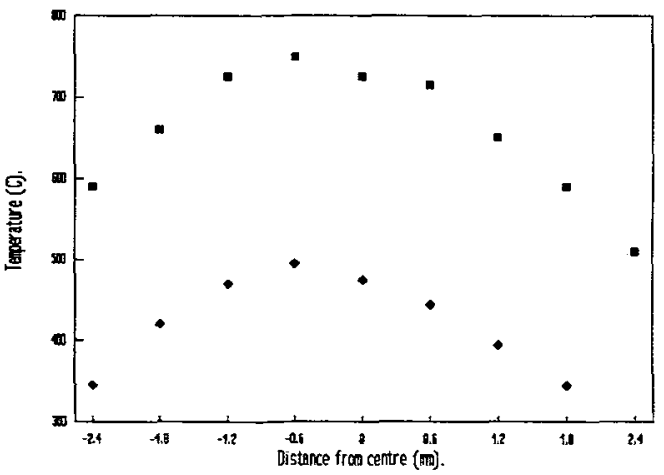

Figure 5 : Temperature profile induced in molybdenum at $17.6 \times 10^{3} \mathrm{~W} / \mathrm{cm}^{2}$ (upper curve) and $9 \times 10^{3} \mathrm{~W} / \mathrm{cm}^{2}$ (lower curve). Displacement of IR-fibre over the width. wider temperature distribution along the surface. The threshold temperature for deposition is exceeded farther away from the irradiated spot. This causes deposition to occur along a greater area on the molybdenum (see fig. 4 and 5). The different microstructures observed are attributed to the non-uniform temperature distribution across the profile track.

Although double humped volcano morphologies have been observed experimentally in the LCVD of different materials $(2,10,15,20)$ it is not yet clear which mechanism is responsible for their occurence. Absorption-desorption processes (2) as well as convection effects (25) are held responsible for the appearance of volcanoes as can be concluded from literature. While further work is needed to determine the exact mechanism responsible for the occurence of volcano-like profiles in the system studied it can be concluded from temperature measurements that volcanoes are formed when the temperature in the centre of the heated region surpasses some critical temperature. In accordance with models described in literature this critical temperature is called the threshold temperature for volcano-like growth (2). TiN growth is distinctly different above and below the threshold temperature for volcano-like growth. Know-how of the dependence of the TiN coating profile on temperature has allowed us to control and optimize the cross-sectional deposit shape. Analysis of a Taguchi experimental design study (not reported here) and the trends found therein (26) corraborated the finding that TiN morphologies and deposit shapes were strongly dependent upon the laser power density used to irradiate the molybdenum substrates. The optimal laser irradiation settings for growing Gaussian-like or flat-topped TiN films were deduced from the Taguchi study. They were found to create a surface temperature profile with the centre temperature between the threshold temperature for decomposition and volcano-like growth. 


\subsection{Deposition of TiN on 3D-formed toul stiels.}

From the previous section it can be concluded that I.CVO of TiN at amospheric pressure is a complicited process. However, with proper selection of the process conditions pure. gold coloured TiN films with good properties can be deposited in a reproducible way. The possibility to kocalize the heat treament and thus the deposition to predefined substrate areas offers distinct advantages e.g. in the coating of lanctional 3D tools with corrosion and wear resistant layers. If complete coating of a tool is to be avoided. unnecessary or uneconomically (hecause only certain parts of the toul are subjected to wear or corrosimn L.CVD might turn out to be the method of choice. To gan knowledere on the possibilitics and problems encountered

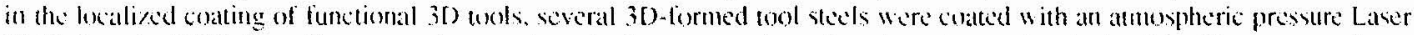
(VD) deposited TiN tilm. Two examples are given in the tlext sections. Based on the results obtained in this area we aim to caltate the portentiat of the method for applying corrosion and wear tesistant layers on an industrial scale:

\subsubsection{Deposition of TiN on D2 (DIN 1.260) tool steel.}

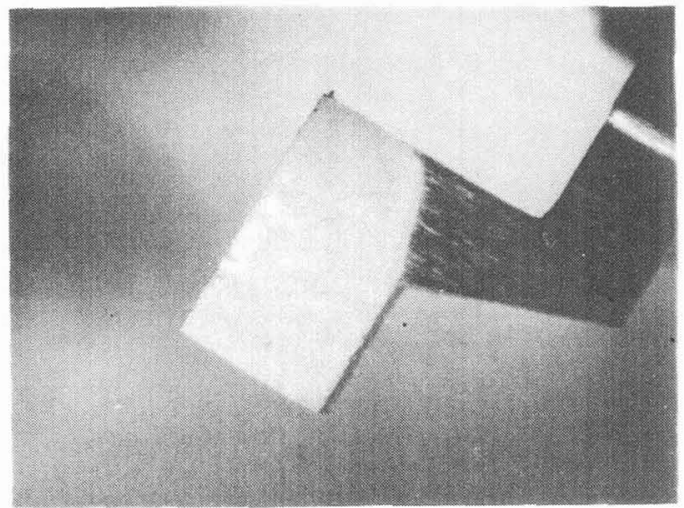

Figure 6: TiN layer on rectangular D2 cube.

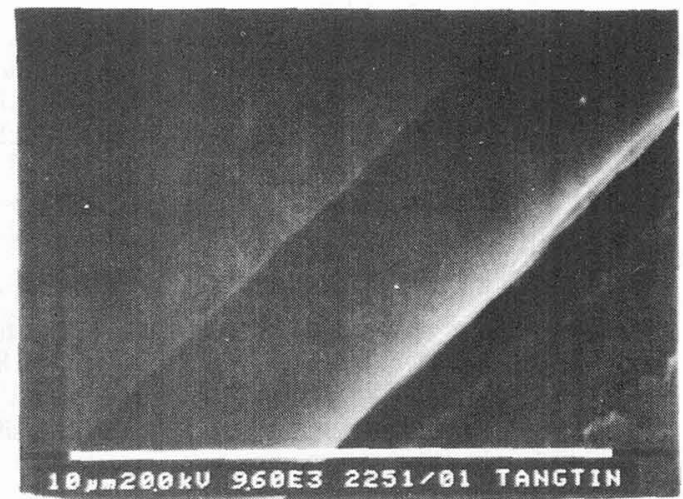

Figure 7 : Cross-section of TiN layer on D2 cube.

The 30-tomed tool steel in this case consist of a small $+x ? \times 1 \mathrm{~mm}$ rectangular shaped D2 tool steel cube connected to a D2 tool steel plate via a thin bent arm. It was the aim of this experiment to deposit a TiN coating locally on the rectangular cube. Ten cubes have been cuated. The Nid-Y AG laser was used at a pulse repetition rate of $300 \mathrm{H} \%$. The pulse width was 1.5 $\mathrm{ms}$. The laser power density was $15 \times 10^{5} \mathrm{~W} / \mathrm{cm}^{2}$. The laser beam was focused on the plane of the cube opposite to the bent arm. The gas flows of $\mathrm{TiCl}_{4}$ and $\mathrm{N}_{2}$ were $1 \mathrm{sccm}$ and $112.5 \mathrm{sccm}$ respectively. The $\mathrm{N}_{2} / \mathrm{H}_{2}$ ratio was 1.5 and the pressure 1 bar. Coating time was 6 min.

The result of the coating experiment is seen in fig. 6 showing the rectangular cube. The golden coloured layer is seen to be restricted nicely to the cube. EDAX revealed the layer to be TiN without any impurities.

A cross-section of a TiN coated cube was analyzed to determine the growth rate of the film and to gain information on the density and the layer thickness distribution of the coating. From SEM-pictures it is clear that a dense, adhering layer of TiN is deposited (see fig.7). The layer thickness distribution on a cross-sectioned cube is schematically drawn in fig.8.

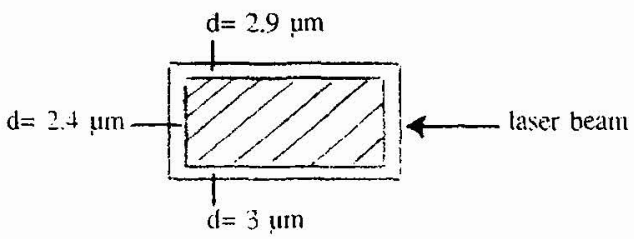

Fig.8: TiN layer thickness distribution orer a cross-sectioned D2 cubx.

A growth rake of $0.4-9.5, \mathrm{~m} / \mathrm{min}$. is observed in this specific application. 


\subsubsection{Deposition of TiN on DIN 1.7405 steel substrates.}

Small ( $4 \times 1.7 \mathrm{~mm}$ ) bent DIN 1.7405 substrates were coated with TiN layers in order to evaluate the deposition on complex curved substrates. The growth rate, thickness distribution, adhesion, hardness and morphology of the deposited layers were studied.

A unfocused Nd-YAG laser beam was irradiated on the substrates through a cylindrical lens. This set-up allowed us to heat the $4 \times 1.7 \mathrm{~mm}$ area rather uniformly. The pulse repetition rate and the pulse width were $400 \mathrm{~Hz}$ and $0.5 \mathrm{~ms}$ respectively. The gas flows and pressure were set to the values stated in section 3.2.1. Coating time ranged from 3 to 5 min.

The result of the coating experiment is seen in fig. 9 showing the TiN layer following nicely the contours of the curved substrate. The growth rate was $0.8 \mu \mathrm{m} / \mathrm{min}$. The thickness distribution over the $4 \mathrm{~mm}$ length was fair although not optimal (mean layer thickness $\pm 10-20 \%$ ) due to optical aberrations of the cylindrical lens. The adhesion of the coating was good as judged from a Rockwell indention made with a $10 \mathrm{~kg}$ preload. No flaking of the coating at the edges of the indention was observed. The hardness was $2100 \pm 200 \mathrm{HV}(1 \mathrm{gf})$. The surface morphology of the deposited films depended strongly on laser output power, rough at high laser powers, smooth at low laser powers.

\section{CONCLUSIONS.}

Pyrolytic LCVD was used for the local deposition of TiN films at atmospheric pressure. Depending on the Nd-YAG laser power density different deposit shapes, distribution widths and microstructures were observed. At high laser power densities, volcano-like TiN deposits were found. At low laser power

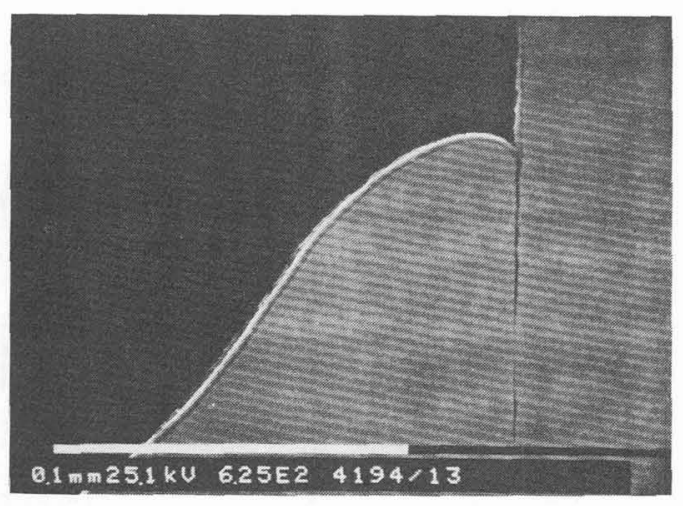
densities Gaussian-like or flat-topped deposits were obtained.

Know-how of the dependence of the TiN coating profile and microstructure on temperature has allowed us to control and optimize the TiN LCVD process at atmospheric pressure in such a way that homogeneous deposits can be formed even on objects of complex geometry. Deposition of TiN films with good properties on 3D-formed tool steels has been demonstrated.

\section{Acknowledgment.}

This work was supported by the Commission of the European Communities in a BRITE/EURAM project BE-3327 under contract BREU-0049-C (GDF).

\section{References.}

[1] Houle F.A.,Jones C.R.,Baum T.H.,Pico C. and Kovac C.A., Appl.Phys.Lett. 46 (1985) 204.

[2] Moylan C.R.,Baum T.H. and Jones C.R., Appl. Phys. A40 (1986) 1.

[3] Baum T.H. and Jones C.R., Appl.Phys.Lett. 47 (1985) 538.

[4] Baum T.H. and Jones C.R., J.Vac. Sci.Technol. B4 (1986) 1187.

[5] Allen S.D., J.Appl.Phys. 52 (1981) 6501.

[6] Petzoldt F.,Piglmayer K.,Kräuter W. and Bäuerle D.,Appl.Phys. A35 (1984) 155.

[7] Bäuerle D.,in Laser Processing and Diagnostics edited by Bäuerle D. (Springer,Berlin,1984) 166.

[8] Allen S.D.,Trigubo A.B. and Jan R.Y., Mater.Res.Soc.Symp.Proc. 17 (1983) 207.

[9] Yokoyama H.,Kishida S. and Washio K., Appl.Phys.Lett. 44 (1984) 755.

[10] Chou W.B.,Azer M.N. and Mazumder J., J.Appl.Phys. 66(1) (1989) 191.

[11] Gluck N.S.,Wolga G.S.,Bartosch C.E.,Ho W. and Ying Z., J.Appl.Phys. 61 (1987) 998.

[12] Schroder H.,Kompa K.L.,Masci D. and Gianinoni I., Appl.Phys. A38 (1985) 227.

[13] Shanov V.,Ivanov B. and Popov C., Thin Solid Films 207 (1992) 71.

[14] Mazumder J.,Allen S.D., Proc.Soc.Photo-Opt.Instrum.Eng. 198 (1980) 73.

[15] Allen S.D., Proc.Soc.Photo-Opt.Instrum.Eng. 198 (1980) 49.

[16] Elders J.,Bebelaar D. and van Voorst J.D.W., Appl.Surf.Sci. 46 (1990) 215.

[17] Chen B.,Biunno N.,Singh R. and Narayan J., Mater.Res.Soc.Symp.Proc. 168 (1990) 287.

[18] Boman M. and Carlsson J.-O., Surf.Coat.Technol. 49 (1991) 221.

[19] Hopfe V.,Baier A. and Scharsig J., Appl.Surf.Sci. 54 (1992) 78.

[20] Conde O.,Ferreira M.L.G.,Hochholdinger P.,Silvestre A. and Vilar R., Appl.Surf.Sci. 54 (1992) 130. 
[21] Westberg H.,Boman M. and Carlsson J.-O., Thin Solid Films 218 (1992) 8.

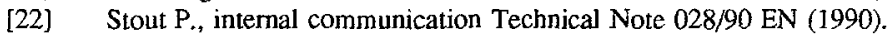

[23] Croonen Y.H., internal communication CTR 542.92.0111 (1992).

[24] Wadman S., internal communication CTR 543.91.0060 (1991).

[25] Allen S.D. and Trigubo A.B., J.Appl.Phys. 54 (1983) 1641.

[26] Croonen Y.H. internal communication CTR 542.93 .0003 (1993). 